\title{
40 issues of ICAME News/ICAME Journal
}

\section{Ilka Mindt, University of Paderborn}

What is known today as the ICAME Journal, celebrating its 40th issue in 2016, started off as a newsletter called ICAME News in 1978. The following brief outline is intended to map some of the most important changes and developments in the publication, taking the contents of all previous issues into consideration. The different text types and their contents have been categorized according to the parameters outlined in what follows.

In 1977, the acronym ICAME referred to the International Computer Archive of Modern English, the founding of which took place in Oslo on 12th February 1977 (see Leech and Johansson 2009: 6). The primary purposes of ICAME, as formulated in the document announcing ICAME, are:

(1) collecting and distributing information on English language material available for computer processing;

(2) collecting and distributing information on linguistic research completed or in progress on material;

(3) compiling an archive of corpuses to be located at the University of Bergen, from where copies of the material could be obtained at cost. (Leech and Johansson 2009: 10).

The ICAME News indeed suited the purpose of distributing information on English language material as well as on linguistic research. The first issue, in March 1978, announced the aims of ICAME and the availability of the American Brown corpus and the completion of the Lancaster-Oslo/Bergen corpus (LOB) and the London-Lund corpus.

In 1984, ICAME News was distributed without charge to almost 400 researchers and research institutions worldwide (Johansson and Hauge 1984: 1). In 1985, the blue square on the front cover was replaced by the red apple logo with a bite on the left and words squeezed in the bitten-off slot. 1986 saw the change of ICAME from a very informal initiative of corpus workers to a more formal organization with an Advisory Board, consisting of 12 members (see 
Johansson 1987: 3). Until 1986 the newsletter was termed 'ICAME News' but was replaced by 'ICAME Journal', starting with issue 11 in 1987. The editor, Stig Johansson, argued that the "change of name [...] is a reflection of the gradual change of our publication, both in appearance and content." (Johansson 1987: 3). The distribution of the newsletter/journal was handled until 2001 by the Bergen Centre, during the period 2001-2005 by Eric Atwell, University of Leeds, and during the period 2006-2013 by Paul Rayson, Lancaster University (see Leech and Johansson 2009: 20). From 2014, the ICAME Journal has been available online on a site hosted by de Gruyter Open and also in hard copies printed and distributed by the same publisher.

The editorial team is truly characterized by stability. Stig Johansson was the leading figure in the publication of ICAME News and was the editor of 15 issues. In 1992, Anna-Brita Stenström joined him in the editorial team. Stig Johansson left the editorial team in 1994, when Merja Kytö and Anna-Brita Stenström took over. They have been responsible for the remaining 23 issues, including the 40th issue in 2016. Jan Aarts joined the editorial team as a review editor in 1994 and stayed for 18 years until 2011 and was replaced in 2012 by Ilka Mindt.

The categorization of all publications in the 39 issues of the newsletter/journal can be broken down into six different types. The most frequent ones are reviews, followed by articles proper - either research articles or articles focussing on the compilation, set-up or annotation of corpora. Next in frequency are articles referred to as 'ICAME services', offering information on the availability of corpora from Bergen, on ICAME projects, on current work on corpora and on digital networking. Articles proper and ICAME services are the two types that can be found in all issues of the newsletter/journal. The development in frequency of the three most frequent article types is reflected in Figure 1: 


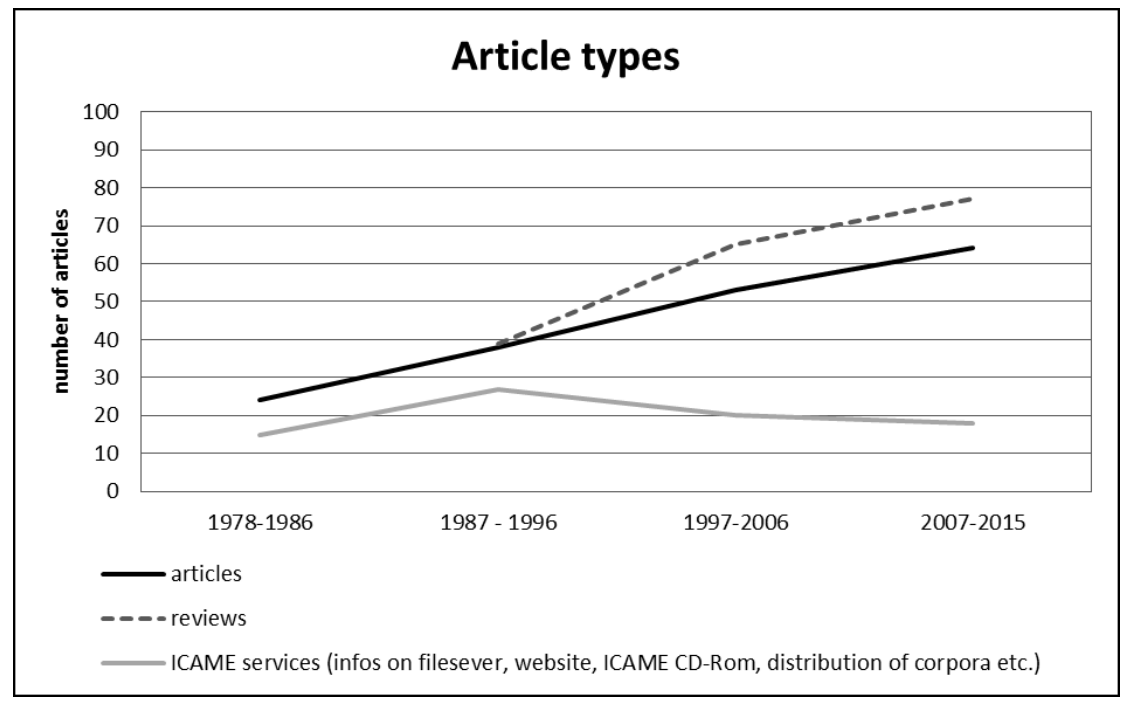

Figure 1: Article types

The three most frequent article types - reviews, articles proper, and ICAME services - are the core of the ICAME News/ICAME Journal. The content of the articles proper is worth focussing on. While the first three issues of the ICAME News contained articles informing on the compilation, set-up and availability of corpora, another type of articles appeared from issue number 4 in 1980: those relating to linguistic work on and with corpora. An investigation of all articles published from the first until the 39th issue shows the results depicted in Figure 2. Articles representing linguistic research on the basis of corpora have been subsumed under one group. The second group comprises articles that deal with corpus compilation, corpus set-up, tagging, software tools etc. 


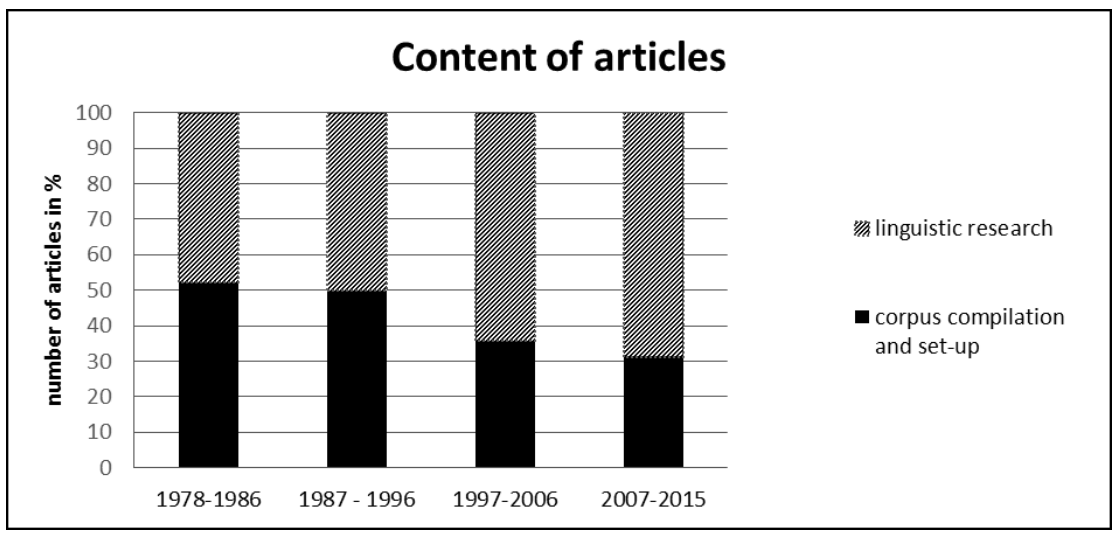

Figure 2: Content of articles

The columns in Figure 2 give the percentages of all articles for a period of ten issues (two appeared in 1979, which explains the mismatch between issues and years). While the first 20 issues show a balance of articles dealing with corpus compilation and set-up on the one hand and linguistic research on corpora on the other, the last 19 issues from 1997 onwards focus in the majority of cases on linguistic research based on corpora. This development is not unexpected, as it shows the change of concerns within corpus linguistics from corpus compilation to research on the material in the corpora. However, corpus compilation and setup is still of relevance in the publications found in the ICAME Journal. This demonstrates the awareness about the design and set-up of corpora which is essential for sound linguistic research.

Three less frequent article types are appreciations, shorter notices and the editor's/editors' foreword. Nine articles termed 'appreciation' have occurred, two of them in the 1986 issue dedicated to W. Nelson Francis, "the pioneer of English computational corpus linguistics" (Altenberg 1986: 3). The 1996 edition boasts five articles that give tribute to W. Nelson Francis and Henry Kučera. "Sidney Greenbaum in memoriam" was published in 1997, and the 33rd issue from 2009 contains an article by Geoffrey Leech and Stig Johansson entitled "The coming of ICAME". Shorter notices cover conference reports on previous ICAME conferences, information about corpora, surveys and other projects related to corpora relevant to the ICAME community. Three issues $(1986,1987$, and 2000) contain an editor's/editors' foreword. 
The role ICAME services have played and still play for ICAME is worth mentioning. ICAME was the first organization worldwide that made its material available to researchers at cost. The corpora were not hidden away but instead offered to those interested in working with corpora. Part of ICAME services is the ICAME network server that was set up in Bergen in 1987 to facilitate the distribution of information and programs, and a mailing list was introduced in 1987. An ftp-server, where files could be uploaded, was established in Bergen in 1991. In addition, a GOPHER server containing ICAME material was run from 1993. The ICAME website started in 1994 and still serves as a main point of information with regard to corpora, manuals and the like. Thanks to the dedicated work of Knut Hofland, ICAME services have ever since been a pillar within the ICAME community.

The ICAME CD-ROM was produced and distributed by the Norwegian Computing Centre for the Humanities in 1992. The first edition contained the Brown Corpus, the LOB Corpus, the Kolhapur Corpus, the London-Lund Corpus and the Helsinki Corpus. The software packages WordCruncher, View, TACT, and Free Text Browser were also distributed on the CD-ROM alongside with the corpora. A second edition of the ICAME CD-ROM was released in 2000. 20 corpora are stored on the $\mathrm{CD}$, amounting to 17 million words. A complete version of WordSmith was also issued on the CD. As of 2015, the ICAME Corpus Collection is available through the CLARIN infrastructure through the Corpuscle system. For more information on ICAME services, see the foreword of the editors (Kytö and Stenström 2000: 5) as well as Wang (2000: 151-154).

The first ICAME bibliography - or better a list of works related to publications on various corpora - was published in ICAME News 2 (1979) listing 57 works. An updated bibliography followed in ICAME News 10 (1986) containing close to 300 items (see Leech and Johansson 2009: 15 and Altenberg 1986: 3). Thanks to the dedicated work of Bengt Altenberg (see also Altenberg 1991) an ICAME bibliography was announced in various other issues (18 (1994) to 21 (1997)). Apart from being available in print, ICAMErs could download it from a fileserver or the ICAME homepage located in Bergen.

What clearly shows that corpus linguistics has become established as a discipline is the publication of reviews in the ICAME Journal. The first review written by Kay Wikberg - appeared in issue 12 (1988) on the Collins COBUILD English language dictionary published by John Sinclair, Patrick Hanks, Gwyneth Fox, Rosamund Moon, and Penny Stock in 1987. Since then the number of reviews has varied from issue to issue from two to 12 .

The acronym ICAME first referred to 'International Computer Archive of Modern English'. This changed with the 21st edition in 1997, when the letter 
$<\mathrm{M}>$ in ICAME additionally referred to 'Medieval' changing the full name into the 'International Computer Archive of Modern and Medieval English'. A distinction is made in Figure 3 between articles proper, focussing on Modern English and those covering 'Medieval' English. All articles that contain a historical component - not necessarily a medieval one - have been subsumed under the label 'medieval'. As the relative frequencies of all articles proper published in the newsletter/journal show, about 26 per cent of the articles are related to historical data. Approximately 14 percent of all reviews cover books focussing on historical research.

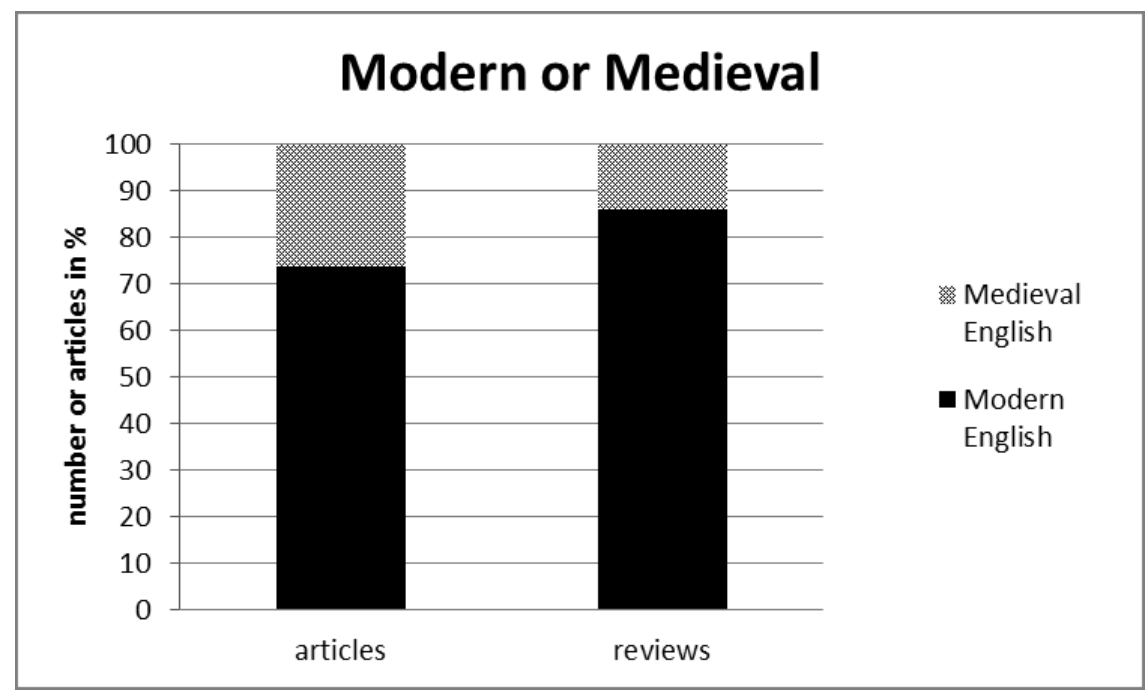

Figure 3: Focus of articles: Modern or medieval

Leech and Johansson (2009) mentioned many changes of ICAME over the years, among them gender distribution. "The founders' meeting was all-male, no doubt reflecting realities in the academic world at that time." (Leech and Johansson 2009: 18). With regard to the articles proper in all 39 issues of the newsletter/journal, 54 per cent have as their first author a male contributor and 46 per cent a female.

This overview of ICAME News/ the ICAME Journal has sketched some developmental stages of the journal: almost 140 different first authors contributed 178 articles proper, 181 reviews were written by 105 reviewers, and 80 
pieces of information about ICAME services were provided by Knut Hofland. The 40th issue clearly demonstrates that the ICAME Journal has grown from a newsletter into a full academic journal. Sadly, the 38 years have also seen the loss of some of the founding fathers and pioneers of ICAME. On a more positive note, thanks to their effort and commitment, ICAME was launched and with it the newsletter/journal. Within English corpus linguistics, the ICAME Journal has established itself as an important publication monitoring the wealth of research and activities which are at the heart of ICAME.

\section{References}

Altenberg, Bengt. 1986. Editor's Foreword. ICAME News 10: 3.

Altenberg, Bengt. 1991. A bibliography of publications relating to English computer corpora. In S. Johansson and A-B. Stenström (eds.). English computer corpora. Selected papers and research guide, 355-396. Berlin and New York: Mouton de Gruyter.

Johansson, Stig. 1987. Editor's Foreword. ICAME Journal 11: 3-4.

Johansson, Stig and Jostein Hauge. 1984. Introduction. ICAME News 8 (1): 1-8. Kytö, Merja, Anna-Brita Stenström and Jan Aarts. 2000. From the Editors. ICAME Journal 24: 5.

Leech, Geoffrey and Stig Johansson. 2009. The coming of ICAME. ICAME Journal 33: 5-20.

Wang, Jianxin. 2000. HIT and ICAME - A visiting researcher's observation. ICAME Journal 24: 151-154. 